OPEN ACCESS

Edited by:

Jixin Zhong,

Case Western Reserve University,

Reviewed by:

Chang Chen,

University of Illinois at Chicago, USA

Xiaojing Yue,

La Jolla Institute for Allergy and

Immunology, USA

Yanlin He,

Baylor College of Medicine, USA

*Correspondence:

Guang-hua Lei

Igh9640@sina.cn

Specialty section:

This article was submitted

to Inflammation,

a section of the journal

Frontiers in Immunology

Received: 09 February 2017

Accepted: 13 March 2017

Published: 30 March 2017

Citation:

Li Y-s, Luo W, Zhu S-a and Lei G-h (2017) T Cells in Osteoarthritis:

Alterations and Beyond.

Front. Immunol. 8:356.

doi: 10.3389/fimmu.2017.00356

\section{T Cells in Osteoarthritis: Alterations and Beyond}

\author{
Yu-sheng Li',2, Wei Luo', Shou-an Zhü and Guang-hua Lei * \\ ${ }^{1}$ Department of Orthopaedics, Xiangya Hospital of Central South University, Changsha, China, ${ }^{2}$ Department of Orthopaedic \\ Surgery, School of Medicine, Johns Hopkins University, Baltimore, MD, USA, ${ }^{3}$ Aging and Metabolism Research Program, \\ Oklahoma Medical Research Foundation, Oklahoma City, OK, USA
}

Although osteoarthritis $(\mathrm{OA})$ has been traditionally regarded as a non-inflammatory disease, reports increasingly suggest that it is inflammatory, at least in certain patients. OA patients often exhibit inflammatory infiltration of synovial membranes by macrophages, T cells, mast cells, B cells, plasma cells, natural killer cells, dendritic cells, granulocytes, etc. Although previous reviews have summarized the knowledge of inflammation in the pathogenesis of OA, as far as we know, no report review our current understanding about $T$ cells, especially, each T cell subtype, in the biology of OA. This review highlights the current understanding of the role of $T$ cells in the pathogenesis of $O A$, with attention to Th1 cells, Th2 cells, Th9 cells, Th17 cells, Th22 cells, regulatory T cells, follicular helper T cells, cytotoxic T cells, T memory cells, and even unconventional T cells (e.g., $\gamma \delta$ $T$ cells and cluster of differentiation 1 restricted T cells). The findings highlight the importance of $T$ cells to the development and progression of OA and suggest new therapeutic approaches for OA patients based on the manipulation of T-cell responses.

Keywords: inflammation, inflammatory diseases, osteoarthritis, T cells, Th17 cells

\section{INTRODUCTION}

Affecting approximately $3.8 \%$ (95\% CI: 3.6-4.1) of the global population, osteoarthritis (OA) is regarded as a prevalent cause of morbidity and disability worldwide (1). OA shows many disease characteristics, such as cartilage degradation, moderate synovial inflammation, pain, alteration of bony structure, and impaired mobility (2). However, despite the severity of the disease, relatively little is known about its exact etiology. Recent compelling investigations have attributed the onset of OA to various person-level factors such as age, sex, obesity, and diet and joint-level factors such as injury, malalignment, and abnormal joint loading (3-5). Although more and more researchers have recently presented hypotheses concerning the involvement of these factors in OA, especially for person-level factors, few of their hypotheses have been demonstrated experimentally, and some have even been challenged by the latest observational studies and clinical trials $(4,6,7)$.

Of the several factors potentially involved in the pathogenesis of OA, T cell-mediated immune responses and their influence on the biology of OA are the focus of this review (8-11). The scientific community once understood OA to be induced by mechanical stress in the form of cartilage destruction, with minimal if any involvement of immune responses. Thus, OA was regarded as a non-inflammatory disease, in contrast with rheumatoid arthritis (RA), an inflammatory disease $(4,7,12,13)$. However, recent studies suggest that at least in certain patients, OA is an inflammatory disease; patients have frequently been found to exhibit inflammatory infiltration of synovial membranes (9-11). Most recent studies have shown that the number of inflammatory cells in the 
synovial tissue is lower in patients with OA than in patients with RA, but higher than that in healthy subjects (14-18). Indeed, little difference has been found in the percentages of T cells, B cells, and natural killer cells in the peripheral blood between patients with OA and RA (19). Leheita et al. (19) reflected on the similarity of the immune cell profiles of RA and OA and suggested that abnormalities in T cells may also contribute to the pathogenesis of OA. Further experiments indicated that inflammation in OA is anatomically restricted and varies in intensity. The synovial membranes in regions rimming the cartilage of OA patients, which contain T cells bordered by B lymphocytes and plasma cells (20), showed a pronounced inflammatory response. In contrast, only a few infiltrating lymphocytes were observed in the synovial membranes taken from macroscopically non-inflamed areas in OA patients (20). This may explain the suggestion made by some researchers that immune responses are not involved in the pathogenesis of OA. When synovial samples from patients with knee OA were analyzed, the synovial lining cells showed strong immunoreactivity and phagocytic potential with cluster of differentiation (CD) 68 antibodies (8). These findings suggested that macrophages may be associated with the pathogenesis of knee OA. Of 20 osteoarthritic synovial membranes, 5 showed lymphoid follicles containing T cells, B cells, and macrophages, and 10 (including the latter five) displayed a diffuse cellular infiltrate containing T and B cells, macrophages, and granulocytes (21). These results suggested that B cells and granulocytes may also be involved in the pathogenesis of knee OA.

To date, various immune cells have been identified in the synovial membranes of OA patients, such as macrophages, T cells, mast cells, B cells, plasma cells, natural killer cells, dendritic cells, and granulocytes $(8,10,22-27)$. For a detailed description of the infiltration of synovial tissues by immune cells, a recent review of this subject should be consulted (10). Of these inflammatory cells, macrophages and $\mathrm{T}$ cells most abundantly infiltrate the synovial tissues of OA patients. For example, macrophages represent approximately $65 \%$ of the immune cells that infiltrate the synovial tissues of patients with OA, and T cells make up $22 \%$ of the infiltrate (17). Although previous reviews have summarized the knowledge of inflammation in the pathogenesis of OA, as far as we know, no report reviews our current understanding about T cells, especially, each T cell subtype, in the biology of OA $(9,10$, 28). More importantly, the scientific community has recently contributed to the growing literature on the involvement of $\mathrm{T}$ cells in the pathogenesis of OA with some interesting findings regarding the alteration of $\mathrm{T}$ cells during OA. Thus, this review focuses on our current understanding of the significance of $\mathrm{T}$ cells to OA biology.

\section{T CELLS AND OA}

Analysis of enzyme-linked immunosorbent assay (ELISA) data has shown that compared with age-matched healthy controls, patients with OA show higher levels of the soluble form of CD4 (sCD4) in their serum. This suggests that peripheral Thelper (Th) cells are involved in the pathogenesis of OA (29). Similarly, when stimulated with phorbol myristate acetate (PMA) and ionomycin, peripheral mononuclear cells from OA patients showed a higher expression of CD4 and CD8 markers than their counterparts from healthy controls (30). Indeed, the ratio of $\mathrm{CD}^{+} / \mathrm{CD}^{+}$ in the blood of OA patients is higher than that in the blood of healthy controls, although healthy controls and OA patients have fairly similar numbers of $\mathrm{CD}^{+}$and $\mathrm{CD} 8^{+} \mathrm{T}$ cells in their blood (31). Further evidence of the involvement of peripheral $\mathrm{T}$ cells in the pathogenesis of OA was provided by the discovery that the response to autologous chondrocytes of peripheral $\mathrm{T}$ cells isolated from OA patients is greater than of peripheral $\mathrm{T}$ cells isolated from controls and that this response is partially blocked by antibodies against human leukocyte antigen (HLA) classes I and II, CD4, and CD8 (32). Interestingly, T cells in a subset of OA patients were found to recognize the peptides representing amino acid regions 16-39 and 263-282 of human cartilage proteoglycan aggrecan (PG), and peripheral blood mononuclear cells from these PG-reactive OA patients showed an increased production of pro-inflammatory cytokines/chemokines in response to PG peptide stimulation (33). Based on these compelling findings, the autoimmune responses of peripheral $\mathrm{T}$ cells may aid understanding of immune-mediated mechanisms in OA.

Enzyme-linked immunosorbent assay analysis revealed higher levels of sCD4 not only in the peripheral blood but also in the synovial fluid of patients with OA, compared with age-matched healthy controls, which suggests that Th cells in the synovial fluid are involved in the pathogenesis of OA (29). When stimulated with PMA and ionomycin, mononuclear cells from the synovial fluid of OA patients showed a high expression of CD4 and CD8 markers (30). These compelling results suggested that $\mathrm{T}$ cells in the synovial fluid are associated with the pathogenesis of OA. This conclusion was supported by subsequent investigations. For example, the percentage of $\mathrm{T}$ cells in the synovial fluid of OA patients was found to be significantly higher than that in their peripheral blood (34), and T cells in the synovial fluid of OA patients expressed class II HLA (an indicator of activated T cells) (35). The percentages of $\mathrm{CD} 4^{+}$and $\mathrm{CD} 8^{+}$cells in the synovial fluid of OA patients were even similar to those found in RA patients (31).

$\mathrm{T}$ cells are the major constituents of synovial infiltrates in the membranes of OA patients, and both $\mathrm{CD}^{+} \mathrm{T}$ cells and $\mathrm{CD} 8^{+} \mathrm{T}$ cells have been found within synovial aggregates (35). For example, synovial tissue extracted from OA patients displayed perivascular $\mathrm{CD}^{+} \mathrm{T}$ cell infiltration at an early stage (36). Similarly, using immunohistochemical analysis, $\mathrm{CD}^{+}, \mathrm{CD}^{+}$, and $\mathrm{CD}^{+} \mathrm{T}$ cells were detected predominantly in the sublining layer and more limitedly in the deep layer of the synovium of patients with OA, whereas the presence of $\mathrm{CD}^{+} \mathrm{T}$ cells in the synovial sublining layer was detected more strongly in OA patients than in normal subjects (15). CD4 ${ }^{+} \mathrm{T}$ cells were found to be predominant among the T-cell infiltrates in the synovial tissue, and the number of $\mathrm{CD} 4^{+} \mathrm{T}$ cells was higher in the synovial sublining layer of patients with $\mathrm{OA}$ than in that of normal subjects. Indeed, the medial synovium of patients with knee OA has been shown to contain more $\mathrm{CD}^{+} \mathrm{T}$ cells than the lateral synovium (8). Interestingly, synovial aggregates from OA patients express CD80, an inducible costimulatory ligand involved in T-cell activation $(35,37)$, suggesting that synovial aggregates in OA patients are areas of antigen recognition and T-cell activation. Similarly, researchers 
investigating 30 patients with $\mathrm{OA}$ found $\mathrm{CD}^{+}{ }^{+} \mathrm{T}$ cell aggregates in the synovial membrane in $65 \%$ of the patients, and the activation antigens CD69, CD25, CD38, CD43, CD45RO, and HLA class II were also found in the synovial membrane (38). In addition, HLA-antigen D-related (DR)-expressing T cells were found in the synovial membranes of OA patients using immunohistochemical analysis, although to a lesser degree than in RA patients (39). The conclusion that activated $\mathrm{T}$ cells are aggregated in the synovial membranes of OA patients was further supported by the discovery that virtually all $\mathrm{T}$ cells in $\mathrm{OA}$ joints express activation markers, such as HLA-DR and CD69 (40). Interestingly, OA patients older than 75 have higher percentages of $\mathrm{CD}^{+}, \mathrm{CD}^{+}$, and $\mathrm{CD}^{+}$cells in their synovial membranes than OA patients younger than 75 (41). This may suggest that age is among the risk factors for OA.

Collectively, significant abnormalities in the T-cell profile have been found in the peripheral blood, synovial fluid, and synovial membranes of OA patients. Based on these findings, $\mathrm{T}$ cells are assumed to be associated with the pathogenesis of OA.

\section{Th1 and OA}

Under the stimulation of interleukin (IL)-12, naïve $\mathrm{CD}^{+} \mathrm{T}$ cells differentiate into Th1 cells, which produce IL-2, interferon (IFN)- $\gamma$, tumor necrosis factor (TNF)- $\alpha$, lymphotoxins, and granulocyte-macrophage colony-stimulating factor (42-44). Most current evidence indicates that Th1 cells do not alter significantly on entering the peripheral blood of OA patients. For example, flow cytometry analysis has shown that there is little difference in the percentage of circulating Th 1 cells $\left(\mathrm{CD} 4^{+} \mathrm{IFN}-\gamma^{+}\right.$ $\mathrm{T}$ cells) between OA patients and healthy controls (45). Similarly, no variation in either the percentage or the absolute number of circulating Th1 cells (CD4 $4^{+} \mathrm{IFN}-\gamma^{+} \mathrm{T}$ cells) has been found between patients with OA and healthy controls (46). However, in a study with $25 \mathrm{OA}$ patients and 13 healthy controls, the number of circulating Th1 cells (IFN- $\gamma^{+} \mathrm{CD} 4^{+} \mathrm{CD} 8^{-} \mathrm{T}$ cells) and the level of serum IFN- $\gamma$ were found to be significantly higher in patients with OA than in healthy controls (47). The difference in the markers $\left(\mathrm{CD} 4^{+}\right.$IFN- $\gamma^{+}$vs. IFN- $\left.\gamma^{+} \mathrm{CD} 4^{+} \mathrm{CD} 8^{-}\right)$used in the two studies to define Th1 cells may account for this discrepancy. Another explanation may lie in the variation between OA patients, such as differences between the stages of OA. The alteration of the Th1 cell profile in the peripheral blood of OA patients thus requires further investigation.

In contrast with the findings for peripheral blood, the synovial fluid of OA patients shows an increase in Th1 cells. Although early experiments suggested that the concentrations of IL-2, IFN$\gamma$, and TNF- $\beta$ in the synovial fluid of OA patients are below the limit of detection by ELISA analysis (48), reverse transcription polymerase chain reaction (RT-PCR) analysis has since revealed that cells from the synovial fluid of OA patients express IL-2 and IFN- $\gamma$ when stimulated with PHA and ionomycin (35). Indeed, intracellular IFN- $\gamma$ has been detected at higher levels in both $\mathrm{CD}^{+}$and $\mathrm{CD}^{+}$cells from the synovial fluid than in the peripheral blood of OA patients (30). In addition, high concentrations of IL- $1 \beta$ and TNF- $\alpha$ have been observed in the synovial fluid of patients with OA, whereas these markers are below the limit of detection in healthy subjects (31).
Th1 cells can also be found in the synovial membranes of OA patients. For example, IL-2, IFN- $\gamma$, and their receptors are usually detected in the synovial membranes of OA patients $(38,49)$. Similarly, INF- $\gamma^{+}$cells have been detected in the synovial membranes of patients with OA, predominantly in the sublining layer of the synovium, although to a lesser degree than in RA patients (15). In a mouse model of OA induced by anterior cruciate ligament transection (ACLT), the expression of IFN- $\gamma$ increased during OA onset (30 days after ACLT) and then decreased at a later stage of OA (90 days after ACLT) (50). Most importantly, a well-designed study showed that Th1 cells are predominant in both OA and RA joints (40). Indeed, the number of IFN- $\gamma^{+}$cells in the synovium of patients with $\mathrm{OA}$ is approximately five times greater than that of IL- $4^{+}$cells (15).

In summary, although the profile of Th1 cells in the peripheral blood requires further analysis, Th1 cells have been shown to accumulate in the synovial fluid and synovial membranes of OA patients, which suggests that Th1 cells play important roles in the pathogenesis of OA. In addition, Th1 cell responses in the synovial fluid and synovial membranes of OA patients may be a marker of OA disease activity.

\section{Th2 and OA}

When stimulated by IL-4, naïve $\mathrm{CD}^{+} \mathrm{T}$ cells differentiate into Th2 cells (44). Through the production of IL-4, IL-5, IL-10, and IL-13, Th2 cells affect the function of B cells, dendritic cells, eosinophils, etc. and play important roles in the host's defense against multicellular parasites and in the pathogenesis of allergies $(42,43,51-54)$. Most recent studies have shown that Th2 cells undergo limited alteration in the peripheral blood, synovial fluid, and synovial membranes of OA patients. For example, in a study of 18 OA patients, the IL-10 transcript was found in nearly all of the patients using competitive PCR analysis, whereas IL-4 and IL- 5 were not detected in the synovial membranes of any of the patients (38). Similarly, the concentrations of IL-4 and IL-10 in the synovial fluid were below the limit of detection by ELISA analysis (48). Using flow cytometry analysis, low concentrations of Th2 cytokines such as IL- 4 and IL-10 were detected in both the synovial fluid and the peripheral blood of OA patients (30). Although cells from the synovial fluid of OA patients stimulated with PHA and ionomycin expressed IL-10 at $48 \mathrm{~h}$ poststimulation, no signal for IL- 4 was detected by RT-PCR analysis (35). The observed expression of IL-10 in OA patients' synovial membranes or synovial fluid cells may come from other cells, such as regulatory T cells (Treg cells).

Together, although these compelling findings suggest that Th2 responses play only a limited role in the pathogenesis of OA, further strong evidence is needed to support this hypothesis.

\section{Th9 and OA}

Th9 cells, recently defined as subsets of Th cells, preferentially produce IL-9 $(44,55-57)$. Th9 cells facilitate immune responses against melanoma and intestinal worms and are closely associated with the immunopathology of allergic and autoimmune responses, such as systemic lupus erythematosus (SLE), experimental autoimmune encephalitis, and systemic sclerosis (55-57). 
Th9 cells are also involved in the pathogenesis of arthritis. For example, a high level of IL-9 has been detected in the peripheral blood and synovial fluid of patients with RA and patients with psoriatic arthritis (PsA), and the level of IL-9 in the synovial fluid is higher than that in the peripheral blood for RA and PsA patients (58). Similarly, activated CD ${ }^{+} \mathrm{T}$ cells from the peripheral blood and synovial fluid of patients with PsA or RA produce high levels of IL-9 (58). These results suggest that Th9 cells play critical roles in the pathogenesis of RA and PsA. Indeed, Th9 responses have also been observed in OA. For example, a high level of IL-9 has been detected in the peripheral blood and synovial fluid of $\mathrm{OA}$ patients, and the activation of purified $\mathrm{CD}^{+}$cells from the peripheral blood and synovial fluid of patients with OA produces a high level of IL-9, although lower than that observed in RA or PsA patients (58). Even more importantly, in a study with $25 \mathrm{OA}$ patients and 13 healthy controls, the number of circulating Th9 cells and serum IL-9 level were found to be significantly higher in OA patients than in healthy controls (47). This study also found that the number of circulating Th9 cells was positively associated with the level of C-reactive protein in OA patients and that both the number of Th9 cells and the level of serum IL-9 were positively correlated with OA index (47).

In summary, these well-designed experiments lead to the conclusion that Th9 cells significantly shape the pathogenesis of OA, as well as that of RA and PsA; however, the Th9 response in the synovial membranes of OA patients needs further investigation. In addition, serum IL-9 or the number of circulating Th9 cells may be a marker of OA disease activity.

\section{Th17 and OA}

Th17 cells secrete IL-17A (also known as IL-17), IL-17F, IL-21, and IL-22. Transform growth factor (TGF)- $\beta$, IL-6, IL-1 $\beta$, and IL-23 have been reported to promote the differentiation of Th17 cells $(44,59-63)$. Th17 cells provide protection against bacterial infection and are associated with the development of autoimmune diseases via the recruitment of cells in the granulocyte lineage, especially neutrophils (64-67). Early investigations indicated that neither the percentages of circulating pure Th17 cells $\left(\mathrm{CD} 4^{+}\right.$ IFN- $\gamma^{-}$IL-22-IL-17 ${ }^{+}$T cells) and Th17 cells (CD4 ${ }^{+}$IL-17 ${ }^{+}$T cells) nor the level of serum IL-17 differed significantly between OA patients and healthy controls (45). Similarly, no variation in the percentage or absolute number of circulating Th17 cells or the IL-17 plasma level was found between patients with OA and healthy controls (46). These findings indicated that little alteration occurs in the Th17 cell profile in the peripheral blood of OA patients. However, later observations suggested otherwise. In a rat model of OA induced by the injection of papain and L-cysteine into the right knee joint, the OA rats were found to have a higher serum IL-17 level than the control rats (68). In addition, in a study with 25 OA patients and 13 healthy controls, the number of circulating Th17 cells and the level of serum IL-17 were found to be significantly higher in patients with OA than in healthy controls (47). As in the case of Th1 cells, variation in the markers used to define Th17 cells $\left(\mathrm{CD} 4^{+} \mathrm{IL}-17^{+}\right.$vs. $\left.\mathrm{IL}-17^{+} \mathrm{CD} 4^{+} \mathrm{CD} 8^{-}\right)$and the patients selected for investigation (e.g., diagnosis standard, disease index, patients' background) may account for this discrepancy. These controversial findings regarding Th17 cell profile in the peripheral blood of OA patients suggest that the roles of circulating Th17 cells in the pathogenesis of OA need further investigation. Nevertheless, it is widely accepted that Th17 cells are present in the synovial fluid and synovial membranes of OA patients. For example, in addition to the strong expression of IL-17 mRNA in the synovial membranes of OA patients (69), a high level of IL-17 has been measured in the synovial fluid of OA patients, whereas both are below the limit of detection in healthy subjects $(31,70)$. In addition, Th17 cells have been detected in the joints of OA patients, albeit in smaller numbers than in RA joints (40).

Collectively, these interesting results demonstrate the accumulation of Th17 cells in the synovial fluid and synovial tissue of OA patients; however, the exact role of Th17 cell response in the biology of OA needs further investigation.

\section{Th22 and OA}

Originally, IL-22 was regarded as a product of Th17 cells; however, recent evidence has indicated that a distinct subset of human skin $\mathrm{CD}^{+} \mathrm{T}$ cells (Th22) produces IL-22 but not IL-17 or IFN- $\gamma(71)$. Increasing evidence has been provided for the involvement of Th22 cells in the biology of RA. For example, the percentage of Th22 cells is higher in RA patients than in healthy controls, and the percentage of Th22 cells is positively correlated with IL-22 expression in RA patients (45). In addition, the percentage of Th22 cells is positively correlated with both C-reactive protein levels and joint disease activity scores in RA patients (45). These compelling discoveries indicate that Th22 response is associated with the pathogenesis of RA and that blocking IL-22 expression may be a reasonable therapeutic strategy for RA. Th22 cells are also involved in the biology of ankylosing spondylitis. Similar to the results for RA, the percentage and absolute number of circulating Th22 cells were found to be elevated in patients with ankylosing spondylitis compared with healthy controls (46). Similarly, ELISA analysis revealed that the level of IL-22 in the plasma was higher in patients with ankylosing spondylitis than in healthy controls (46). However, Th22 cells seem to play a limited role in the pathogenesis of OA. For example, compared with healthy controls, OA patients show no change in the percentage of circulating Th22 cells $\left(\mathrm{CD} 4^{+}\right.$ IFN- $\gamma^{-}$IL-17-IL-22 ${ }^{+}$T cells) and the level of IL-22 in the plasma (45). Similarly, another independent experiment revealed that neither the percentage nor the absolute number of circulating Th22 cells, nor the plasma level of IL-22, differ between patients with OA and healthy controls (46).

Collectively, unlike RA and ankylosing spondylitis, OA involves only a limited alteration of Th22 response in the peripheral blood; however, we lack data on the Th22 profile in the synovial fluid and synovial tissue of OA patients.

\section{Treg Cells and OA}

Under the influence of TGF- $\beta$, naivve T cells differentiate into Treg cells, which produce IL-10 and TGF- $\beta$ (43, 72-74). Treg cells are important immunoregulators in many inflammatory and autoimmune diseases, as they modulate the secretion of anti-inflammatory cytokines and the expression of receptors for cytokines (75). For example, RA patients have a lower 
percentage of Treg cells at sites of synovial inflammation and in the peripheral blood (76), which may induce the downregulation of T-cell tolerance and exacerbate the inflammatory process. Increasing evidence has been provided that the profile of Treg cells in the peripheral blood, synovial fluid, and synovial membranes of OA patients is similar to that of RA patients. For example, the percentage and absolute number of Treg cells (CD4 ${ }^{+}$ $\mathrm{CD} 25^{\text {+high }} \mathrm{CD} 127^{- \text {llow }}$ ) in the peripheral blood, synovial fluid, and synovial membranes are similar in RA patients and OA patients, and Treg cells in both cases show greater accumulation in the synovial fluid and synovial membranes than in the peripheral blood (77). In addition, Treg cells in the peripheral blood, synovial fluid, and synovial membranes of both OA patients and RA patients display a memory phenotype $\left(\mathrm{CD} 45 \mathrm{RO}^{+} \mathrm{RA}^{-}\right)(77)$. Neither does the activation status (CD69 and CD62L) nor the expression of markers associated with Treg function (CD152, CD154, CD274, CD279, and GITR) in the peripheral blood, synovial fluid, or synovial membranes differ between OA patients and RA patients (77). Those compelling results indicate that as in the case of RA, a decrease in Treg-cell responses is involved in the pathogenesis of OA. Indeed, Ponchel et al. (11) analyzed blood from 121 healthy controls and 114 OA patients and found that the OA patients had fewer Treg cells than the healthy controls after adjusting for age (11). Although the frequency of $\mathrm{CD} 4^{+} \mathrm{CD} 25^{+} \mathrm{Foxp} 3^{+}$Treg cells has been found to be elevated in the blood of OA patients, OA patients show lower IL-10 secretion from Treg cells and fewer Tim $-3^{+}$Treg cells in the blood (78). Similarly, in a rat model of OA induced by the injection of papain and $\mathrm{L}$-cysteine into the right knee joint, the percentage of $\mathrm{CD} 4{ }^{+} \mathrm{CD} 25^{+} \mathrm{Foxp} 3^{+}$Treg cells in the peripheral blood was significantly lower in the OA rats than in the control rats (68).

In summary, a decrease in Treg-cell response may be involved in the pathogenesis of OA; however, the alteration of Treg-cell responses in the peripheral blood, synovial fluid, and synovial membranes of OA patients requires more comparative investigation with age-matched healthy controls.

\section{Follicular Helper T (Tfh) Cells and OA}

Follicular helper T cells, located in the follicles of lymphoid tissue, induce B cells to produce immunoglobulins (79). Tfh cells express various distinguishing genes, such as CXCR5, PD-1, ICOS, CD 40L, Bcl-6, and IL-21 (80). Increasing evidence has been provided for the influence of Tfh cells on the severity of autoimmune diseases, such as SLE and RA. For example, the number of circulating Tfh cells $\left(\mathrm{CXCR} 5^{+} \mathrm{ICOS}^{+} \mathrm{CD} 4^{+}\right.$cells or $\mathrm{CXCR} 5^{+} \mathrm{PD}-1^{+} \mathrm{CD} 4^{+}$cells) has been shown to increase in a subset of SLE patients in line with the diversity and concentration of autoantibodies and SLE severity (81). Similarly, immunohistochemistry analysis has revealed specific staining for CD4, CXCR5, and ICOS on infiltrating immune cells in the synovial tissues of RA patients, and the presence of Tfh cells $\left(\mathrm{CD}^{+} \mathrm{CXCR}^{+} \mathrm{ICOS}^{+} \mathrm{T}\right.$ cells) in the synovial tissues of RA patients has been verified using both triple-fluorescence immunostaining and confocal laser scanning (82). This study provided evidence of the presence of Tfh cells in both SLE and RA patients, indicating the potentially important roles played by Tfh cells in the pathogenesis and progression of both diseases. However, the results of immunohistochemistry analysis, triple-fluorescence immunostaining, and confocal laser scanning revealed that Tfh cells are absent from the synovial tissues of OA patients (82). Yet, a recent investigation demonstrated the importance of Tfh cells to the pathogenesis and progression of OA. In the latter study, the frequency of ICOS ${ }^{+}, \mathrm{PD}-1^{+}$, and $\mathrm{IL}-21^{+} \mathrm{CXCR}^{+} \mathrm{CD} 4^{+} \mathrm{T}$ cells in the peripheral blood of 40 patients with $\mathrm{OA}$ and 13 healthy controls was examined by flow cytometry, and the concentration of serum IL-21 was also determined. Compared with the healthy controls, the OA patients showed higher percentages of $\mathrm{CXCR}^{+} \mathrm{CD}^{+}, \mathrm{PD}-1^{+} \mathrm{CXCR}^{+} \mathrm{CD}^{+}, \mathrm{ICOS}^{+} \mathrm{CXCR} 5^{+} \mathrm{CD} 4^{+}$, and IL-2 $1^{+} \mathrm{CXCR} 5^{+} \mathrm{CD} 4^{+} \mathrm{T}$ cells (83). Shan et al. (83) also found that OA patients exhibited higher levels of serum IL-21 than healthy controls and, even more importantly, that the expression of IL-2 $1^{+}$Tfh cells in OA patients was positively correlated with the disease activity of OA (83). The latter study suggests that Tfh cells play a critical role in the pathogenesis and progression of OA. However, further well-designed research is needed to characterize Tfh cell profile in the peripheral blood, synovial fluid, and synovial membranes of OA patients.

\section{Cytotoxic T Cells and OA}

The peripheral blood of OA patients has been analyzed using flow cytometry, revealing that patients with OA have significantly fewer $\mathrm{CD}^{+} \mathrm{T}$ cells and a higher $\mathrm{CD}^{+}: \mathrm{CD}^{+}$ratio than healthy subjects (84). However, patients with OA have normal proportions of $\mathrm{CD}^{+}{ }^{+} \mathrm{CD} 45 \mathrm{RA}^{+}, \mathrm{CD}^{+} \mathrm{CD} 29^{+}$, and $\mathrm{CD} 8{ }^{+} \mathrm{S} 6 \mathrm{~F} 1^{+}$cells in both their peripheral blood and their synovial fluid (85). These results indicate the alteration of peripheral $\mathrm{CD} 8^{+} \mathrm{T}$ cells in $\mathrm{OA}$ patients. Although $\mathrm{CD}^{+} \mathrm{T}$ cells can be found in the synovial membranes of OA patients, the major component of the T-cell infiltrate cannot. Most of the T cells found in the synovial membranes of patients with OA are helper T cells, whereas cytotoxic $\mathrm{T}$ cells occur sparsely in patients with $\mathrm{OA}(39,86)$. Similarly, fewer $\mathrm{CD}^{+} \mathrm{T}$ cells than $\mathrm{CD} 4^{+} \mathrm{T}$ cells have been found in the lining, the sublining, and even the deep layer of the synovium of patients with OA (15). In addition, although both $\mathrm{CD}^{+}$and $\mathrm{CD}^{+} \mathrm{T}$ cells have been found in the synovial aggregates of OA patients, the aggregates contain a larger proportion of $\mathrm{CD}^{+}$ $\mathrm{T}$ cells than of $\mathrm{CD} 8^{+} \mathrm{T}$ cells, and the $\mathrm{CD} 8^{+} \mathrm{T}$ cells are often located toward the periphery of the aggregates (35). $\mathrm{CD}^{+} \mathrm{T}$ cells play an important role in the pathogenesis of OA, although they are not the predominant $\mathrm{T}$-cell type found in the synovial aggregates of OA patients. In mice with ACLT-induced OA, CD8 ${ }^{+} \mathrm{T}$ cells were activated once $\mathrm{OA}$ had been initiated, and the percentage of activated $\mathrm{CD}^{+} \mathrm{T}$ cells was significantly higher in the ACLT group than in the sham group during OA progression (87). In addition, the number of $\mathrm{CD}^{+} \mathrm{T}$ cells expressing tissue inhibitor of metalloproteinase-1 (TIMP-1) was found to be correlated with OA severity and inhibiting the expression of TIMP-1 in the joints retarded the progression of OA (87). Cartilage degeneration occurred more slowly in $\mathrm{CD}^{+} \mathrm{T}$ cell knockout mice than in wild-type mice (87).

In summary, a significant alteration to $\mathrm{CD}^{+} \mathrm{T}$ cells has been observed in the peripheral blood, the synovial fluid, and the synovial membranes, and $\mathrm{CD}^{+} \mathrm{T}$ cells have been found to significantly shape the pathogenesis of OA, although they do not play the most important role in the process. 


\section{T Memory (Tm) Cells and OA}

Once activated, most $\mathrm{T}$ cells undergo apoptosis; however, a minority persist as Tm cells. An increasing number of researchers have begun to investigate the profile of Tm cells in the pathogenesis of OA. For example, although healthy individuals showed no difference in the percentages of $\mathrm{CD} 45 \mathrm{RO}^{+} \mathrm{CD} 4^{+} \mathrm{T}$ cells and

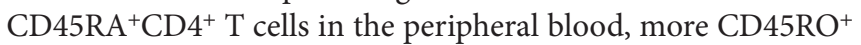
cells than CD45RA ${ }^{+}$cells were found in the peripheral blood of patients with $\mathrm{OA}(88)$. In patients with $\mathrm{OA}$, the majority of $\mathrm{CD}^{+}$ $\mathrm{T}$ cells in the synovial fluid and synovial tissue are $\mathrm{CD} 45 \mathrm{RO}^{+}$

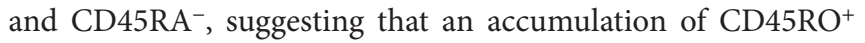
memory $\mathrm{CD}^{+}{ }^{+} \mathrm{T}$ cells is a generalized phenomenon in $\mathrm{OA}$ joints (88). Similarly, a study with $25 \mathrm{OA}$ patients and 13 healthy controls revealed that the number of circulating $\mathrm{CD} 4^{+} \mathrm{CD} 45 \mathrm{RO}^{+} \mathrm{T}$ cells was significantly higher in patients with $\mathrm{OA}$ than in healthy controls (47). Other evidence for the possible involvement of Tm cells in the pathogenesis of $\mathrm{OA}$ includes the detection of the regulated on activation, normal $\mathrm{T}$ cell expressed, and secreted chemokine (a potent chemoattractant for leukocytes, such as $\mathrm{CD}_{45 \mathrm{RO}^{+}}$ memory T cells) and CD29 (a 1 integrin expressed by Tm cells) in the synovial fluid of OA patients $(35,37,89)$.

In summary, $\mathrm{CD} 45 \mathrm{RO}^{+}$memory $\mathrm{CD}^{+} \mathrm{T}$ cells seem to be critical to the biology of OA, yet their exact roles in the pathogenesis of OA have yet to be determined.

\section{Unconventional T Cells and OA}

Recent investigations have also highlighted the involvement of unconventional $\mathrm{T}$ cells in the pathogenesis of OA. For example, more and more evidence has been provided that $\gamma \delta \mathrm{T}$ cells are involved in the pathogenesis of RA. For example, the number of $\gamma \delta \mathrm{T}$ cells has been found to increase in the synovial membranes of RA patients (90-93), and $\gamma \delta$ T cells in the synovial membranes have more and/or more avid Fc receptors for immunoglobulin G IgG in patients with RA compared with controls (90). Further research has shown that the majority of synovial $\gamma \delta$ T cells in RA patients do not express $\mathrm{V} \gamma 9$, V $\delta 2$, or V $\delta 1-\mathrm{J} \gamma \delta 1$ (91). However, most recent studies have indicated that the number of $\gamma \delta \mathrm{T}$ cells in the synovial membranes of patients with OA does not increase (91-93). Immunohistochemical staining of synovial tissue with early-stage OA shows T-cell infiltration in the perivascular area, with the clonality of restricted $\mathrm{T}$ cell receptor usage in the $\mathrm{V}$ beta chain (36), which also indicates the minimal alteration of $\gamma \delta \mathrm{T}$ cells in OA patients. Recent studies have shown that the synovial membranes of OA patients express CD1 (94), which presents non-protein antigens to NKT cells, suggesting that CD1-restricted T cells may play a role in the pathogenesis of OA.

Overall, although numerous studies of the involvement of conventional $\mathrm{T}$ cells in OA have been conducted, it will be useful to determine the importance to OA of unconventional $\mathrm{T}$ cells such as CD1-restricted T cells, MR1-restricted mucosalassociated invariant $\mathrm{T}$ cells, major histocompatibility complex class Ib-reactive T cells, and $\gamma \delta$ T cells (95).

\section{CONCLUSION}

Various risk factors for OA have been proposed, ranging from person-level factors such as age, sex, and obesity, to joint-level factors such as injury, malalignment, and abnormal loading of

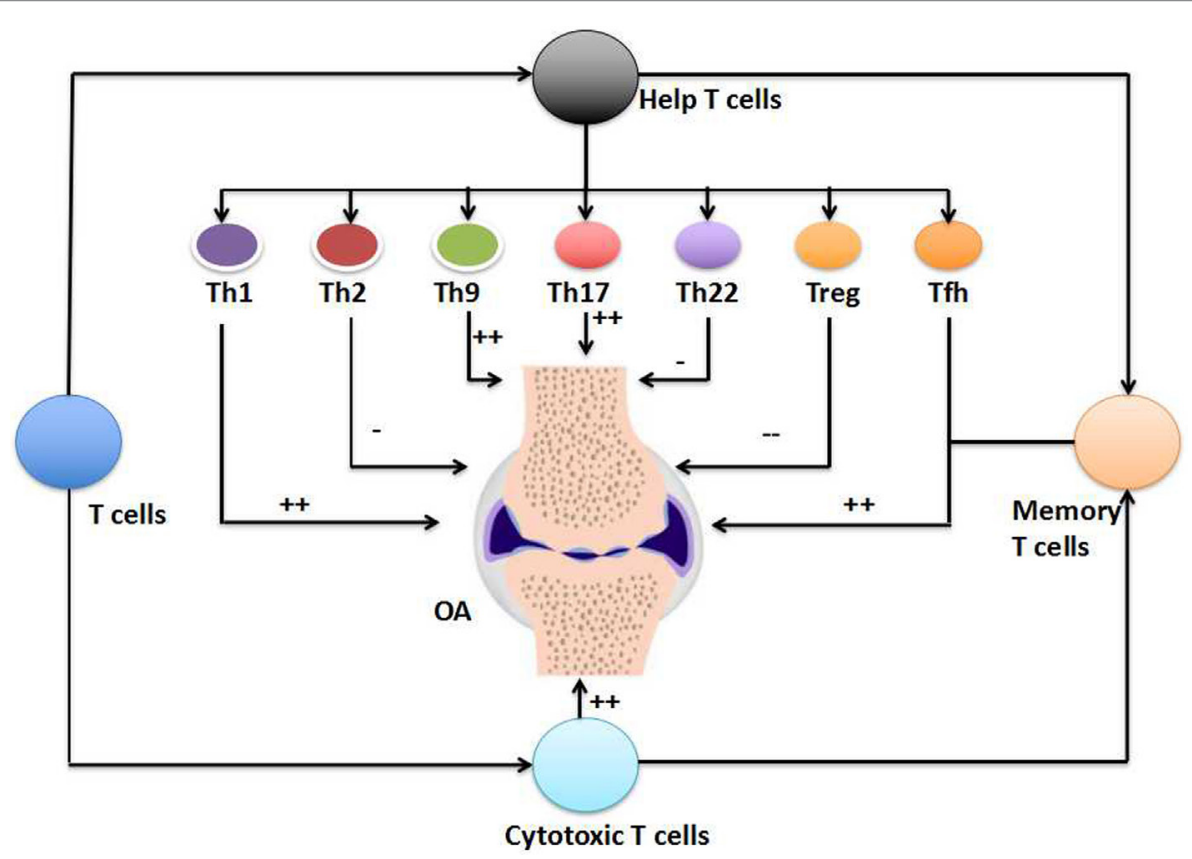

FIGURE 1 | The involvement of T cells in the pathogenesis of osteoarthritis (OA). T cells, including the $T$ helper (Th) cells, cytotoxic $T$ cells, and T memory $(\mathrm{Tm})$ cells, have critical importance in the pathogenesis of $\mathrm{OA}(++)$. The involvement of unconventional $\mathrm{T}$ cells in the pathogenesis of OA is not shown here. Within $\mathrm{T}$ helper (Th) cells, Th1 cells, Th9 cells, Th17 cells, and follicular helper T (Tfh) cells increase in the peripheral blood, synovial fluid, or synovial membranes of OA patients (++). The numbers of cytotoxic T cells and Tm cells also increase in the OA. However, the numbers of Th2 cells and Th22 cells show limited alteration in the pathogenesis of OA (-), but the number of Treg cells decrease during the OA (--). 
TABLE 1 | The alteration of Th subset cells in OA.

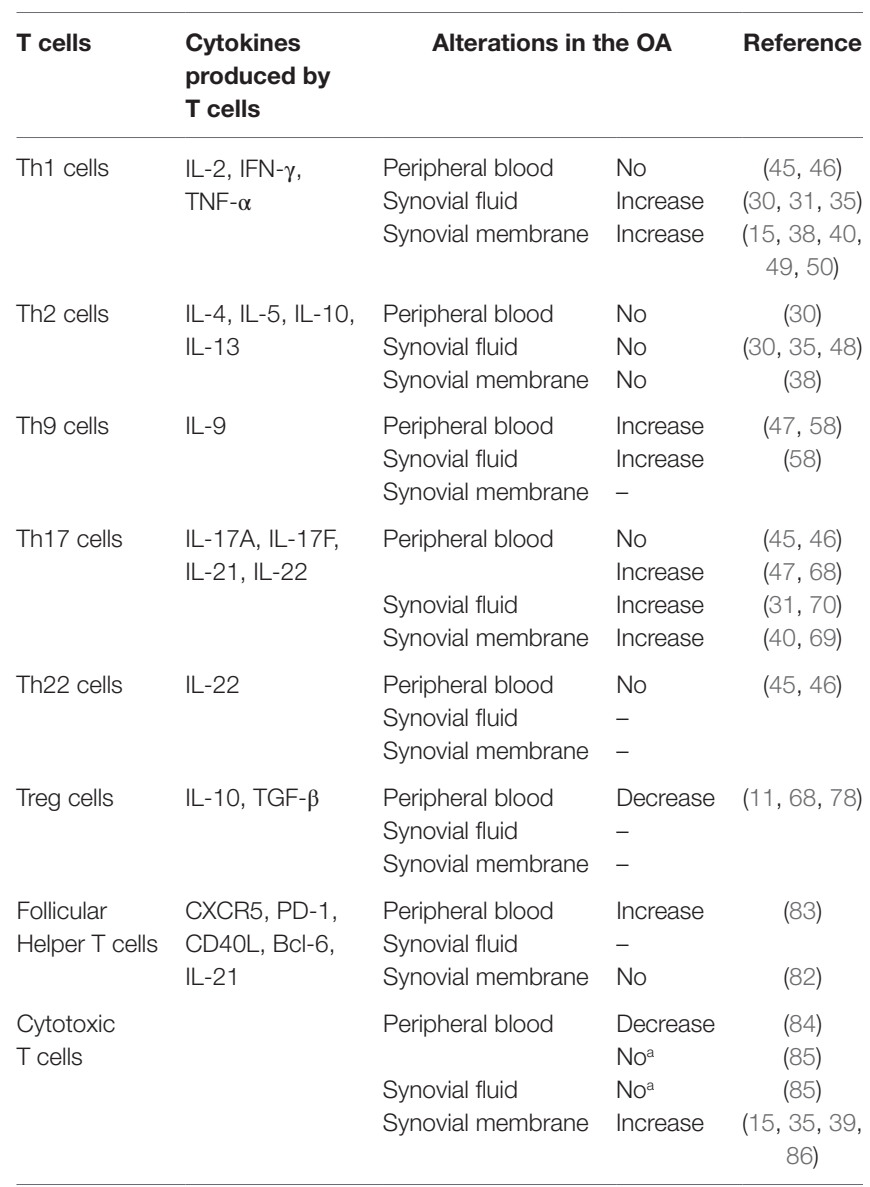

IL, interleukin; IFN, interferon; TNF, tumor necrosis factor; TGF, transform growth factor; CXCR5, C-X-C chemokine receptor type 5; $P D-1$, programmed death 1 ; -, further investigations are needed; $O A$, osteoarthritis; Th, Thelper; Treg, regulatory $T$. ${ }^{a} \mathrm{CD} 8^{+} \mathrm{CD} 45 \mathrm{RA}^{+}, \mathrm{CD} 8^{+} \mathrm{CD} 29^{+}$, and $\mathrm{CD} 8^{+} \mathrm{S} 6 \mathrm{~F}{ }^{+}+$cells.

joints (3-5). Increasing evidence has also been provided that inflammation is associated with the development and progression of OA, at least in certain patients. OA patients often exhibit the infiltration of synovial membranes by inflammatory cells such as macrophages, T cells, mast cells, B cells, plasma cells, natural killer cells, dendritic cells, and granulocytes (8-11). Several scholars have investigated the alteration of $\mathrm{T}$ cells during the pathogenesis of OA, with reference to Th1 cells, Th2 cells, Th9 cells, Th17 cells, Th22 cells, Treg cells, Tfh cells, cytotoxic T cells, Tm cells, and even unconventional $\mathrm{T}$ cells (e.g., $\gamma \delta \mathrm{T}$ cells and CD1-restricted $\mathrm{T}$ cells). To date, it has been widely accepted that a significant alteration occurs in the profiles of Th1 cells, Th9 cells, Th17 cells, Treg cells, cytotoxic T cells, and Tm cells in the peripheral blood, synovial fluid, and synovial membranes of OA patients (Figure 1; Table 1). However, the involvement of Th2 cells, Th22 cells, Tfh

\section{REFERENCES}

1. Cross M, Smith E, Hoy D, Nolte S, Ackerman I, Fransen M, et al. The global burden of hip and knee osteoarthritis: estimates from the global burden of disease 2010 study. Ann Rheum Dis (2014) 73(7):1323-30. doi:10.1136/ annrheumdis-2013-204763 cells, and unconventional T cells in the pathogenesis of OA needs further investigation (Figure 1; Table 1). In addition, the causal relationship between the alteration of T-cell responses and the development and progression of OA has yet to be identified. Various factors such as extracellular stimulation (e.g., antigens), intracellular signaling [e.g., mTOR complex 1 (mTORC1)], and cell metabolism (e.g., amino acid metabolism) are significant determinants of the fate of T cells $(54,66,96-100)$. Therefore, it will be interesting to manipulate these factors to determine their precise effects on the development and progression of OA. For example, $\mathrm{mTORC} 1$ is known to regulate Th17 differentiation and IL-17 expression through several pathways, including STAT3, HIF-1 $\alpha$, S6K1, and S6K2, which raises the possibility of regulating the pathogenesis of OA through mTORC1 signaling (66). Indeed, the great importance of mTORC1 signaling to the pathogenesis of OA has recently been highlighted (101). The metabolism and transportation of amino acids also have a remarkable influence on T-cell activation and differentiation, especially for Th1 and Th17 cells, suggesting that amino acid metabolism also affects the pathogenesis of OA. Indeed, the establishment and development of OA are associated with alterations in the metabolism and profile of amino acids such as those of the glutamate and arginine families, as well as their related metabolites (e.g., creatinine, hydroxyproline, $\gamma$-aminobutyrate, dimethylarginines, and homoarginine) (4). Furthermore, intestinal microbiota have vital roles in T-cell responses, especially those of Th17 cells (102, 103), indicating the critical functions of intestinal microbiota in the pathogenesis of OA. Indeed, intestinal microbiota have been proposed as a risk factor in the development and progression of OA $(7,104)$. Understanding the significance of the altered T-cell profile to the pathogenesis of OA will open up novel directions for preventing and treating $\mathrm{OA}$ by modulating $\mathrm{T}$-cell responses.

\section{AUTHOR CONTRIBUTIONS}

Y-sL and G-hL conceived this study. Y-sL wrote the manuscript. WL and S-aZ provided critical discussion in manuscript preparation. G-hL revised the manuscript.

\section{ACKNOWLEDGMENTS}

We thank Prof. Ping Yu (Department of Immunology, Xiangya School of Medicine, Central South University) for her constructive comments. This work was supported by the National Natural Science Foundation of China (No. 814721308, 81402224, and 81401838), the Provincial Science Foundation of Hunan (No. 2015JJ3139), the Key Research and Development Program of Hunan Province (2016JC2038), the Health and Family Planning Commission of Hunan Province (B2014-12), the Administration of TraditionalChinese Medicine of Hunan Province(No.2015116), and the China Scholarship Council (student ID: 201606375101).

2. Bingham CO III, Buckland-Wright JC, Garnero P, Cohen SB, Dougados M, Adami S, et al. Risedronate decreases biochemical markers of cartilage degradation but does not decrease symptoms or slow radiographic progression in patients with medial compartment osteoarthritis of the knee: results of the two-year multinational knee osteoarthritis structural arthritis study. Arthritis Rheum (2006) 54(11):3494-507. doi:10.1002/art.22160 
3. Felson DT, Lawrence RC, Dieppe PA, Hirsch R, Helmick CG, Jordan JM, et al. Osteoarthritis: new insights. Part 1: the disease and its risk factors. Ann Intern Med (2000) 133(8):635-46. doi:10.7326/0003-4819-133-8-20001017000016

4. Li Y, Xiao W, Luo W, Zeng C, Deng Z, Ren W, et al. Alterations of amino acid metabolism in osteoarthritis: its implications for nutrition and health. Amino Acids (2016) 48(4):907-14. doi:10.1007/s00726-015-2168-x

5. Malfait AM. Osteoarthritis year in review 2015: biology. Osteoarthritis Cartilage (2016) 24(1):21-6. doi:10.1016/j.joca.2015.09.010

6. Zhang F, Luo W, Li Y, Gao S, Lei G. Role of osteopontin in rheumatoid arthritis. Rheumatol Int (2015) 35(4):589-95. doi:10.1007/s00296-014-3122-Z

7. Li Y, Luo W, Deng Z, Lei G. Diet-intestinal microbiota axis in osteoarthritis: a possible role. Mediators Inflamm (2016) 2016:3495173. doi:10.1155/2016/3495173

8. Saito I, Koshino T, Nakashima K, Uesugi M, Saito T. Increased cellular infiltrate in inflammatory synovia of osteoarthritic knees. Osteoarthritis Cartilage (2002) 10(2):156-62. doi:10.1053/joca.2001.0494

9. Sakkas LI, Platsoucas CD. The role of T cells in the pathogenesis of osteoarthritis. Arthritis Rheum (2007) 56(2):409-24. doi:10.1002/art.22369

10. de Lange-Brokaar BJ, Ioan-Facsinay A, van Osch GJ, Zuurmond AM, Schoones J, Toes RE, et al. Synovial inflammation, immune cells and their cytokines in osteoarthritis: a review. Osteoarthritis Cartilage (2012) 20(12):1484-99. doi:10.1016/j.joca.2012.08.027

11. Ponchel F, Burska AN, Hensor EM, Raja R, Campbell M, Emery P, et al. Changes in peripheral blood immune cell composition in osteoarthritis. Osteoarthritis Cartilage (2015) 23(11):1870-8. doi:10.1016/j.joca.2015. 06.018

12. Hugle T, Geurts J. What drives osteoarthritis? - synovial versus subchondral bone pathology. Rheumatology (Oxford) (2016). doi:10.1093/rheumatology/ kew389

13. Withrow J, Murphy C, Liu Y, Hunter M, Fulzele S, Hamrick MW. Extracellular vesicles in the pathogenesis of rheumatoid arthritis and osteoarthritis. Arthritis Res Ther (2016) 18(1):286. doi:10.1186/s13075-016-1178-8

14. Fonseca JE, Edwards JC, Blades S, Goulding NJ. Macrophage subpopulations in rheumatoid synovium: reduced CD163 expression in CD4+ T lymphocyte-rich microenvironments. Arthritis Rheum (2002) 46(5):1210-6. doi:10.1002/art.10207

15. Ishii H, Tanaka H, Katoh K, Nakamura H, Nagashima M, Yoshino S. Characterization of infiltrating $\mathrm{T}$ cells and Th1/Th2-type cytokines in the synovium of patients with osteoarthritis. Osteoarthritis Cartilage (2002) 10(4):277-81. doi:10.1053/joca.2001.0509

16. Diaz-Torne C, Schumacher HR, Yu X, Gomez-Vaquero C, Dai L, Chen LX, et al. Absence of histologic evidence of synovitis in patients with Gulf War veterans' illness with joint pain. Arthritis Rheum (2007) 57(7):1316-23. doi:10.1002/art.23006

17. Pessler F, Chen LX, Dai L, Gomez-Vaquero C, Diaz-Torne C, Paessler ME, et al. A histomorphometric analysis of synovial biopsies from individuals with Gulf War Veterans' Illness and joint pain compared to normal and osteoarthritis synovium. Clin Rheumatol (2008) 27(9):1127-34. doi:10.1007/ s10067-008-0878-0

18. Rollin R, Marco F, Jover JA, Garcia-Asenjo JA, Rodriguez L, Lopez-Duran $\mathrm{L}$, et al. Early lymphocyte activation in the synovial microenvironment in patients with osteoarthritis: comparison with rheumatoid arthritis patients and healthy controls. Rheumatol Int (2008) 28(8):757-64. doi:10.1007/ s00296-008-0518-7

19. Leheita O, Abed Elrazek NY, Younes S, Mahmoud AZ. Lymphocytes subsets in osteoarthritis versus rheumatoid arthritis. Egypt J Immunol (2005) 12(2):113-24.

20. Lindblad S, Hedfors E. Arthroscopic and immunohistologic characterization of knee joint synovitis in osteoarthritis. Arthritis Rheum (1987) 30(10):10818. doi:10.1002/art.1780301001

21. Revell PA, Mayston V, Lalor P, Mapp P. The synovial membrane in osteoarthritis: a histological study including the characterisation of the cellular infiltrate present in inflammatory osteoarthritis using monoclonal antibodies. Ann Rheum Dis (1988) 47(4):300-7. doi:10.1136/ard.47.4.300

22. Kummer JA, Tak PP, Brinkman BM, van Tilborg AA, Kamp AM, Verweij CL, et al. Expression of granzymes A and B in synovial tissue from patients with rheumatoid arthritis and osteoarthritis. Clin Immunol Immunopathol (1994) 73(1):88-95. doi:10.1006/clin.1994.1173
23. Pettit AR, Ahern MJ, Zehntner S, Smith MD, Thomas R. Comparison of differentiated dendritic cell infiltration of autoimmune and osteoarthritis synovial tissue. Arthritis Rheum (2001) 44(1):105-10. doi:10.1002/ 1529-0131(200101)44:1<105:AID-ANR14>3.0.CO;2-3

24. Benito MJ, Veale DJ, FitzGerald O, van den Berg WB, Bresnihan B. Synovial tissue inflammation in early and late osteoarthritis. Ann Rheum Dis (2005) 64(9):1263-7. doi:10.1136/ard.2004.025270

25. Da RR, Qin Y, Baeten D, Zhang Y. B cell clonal expansion and somatic hypermutation of Ig variable heavy chain genes in the synovial membrane of patients with osteoarthritis. J Immunol (2007) 178(1):557-65. doi:10.4049/ jimmunol.178.1.557

26. Nakano S, Mishiro T, Takahara S, Yokoi H, Hamada D, Yukata K, et al. Distinct expression of mast cell tryptase and protease activated receptor-2 in synovia of rheumatoid arthritis and osteoarthritis. Clin Rheumatol (2007) 26(8):1284-92. doi:10.1007/s10067-006-0495-8

27. Lebre MC, Jongbloed SL, Tas SW, Smeets TJ, McInnes IB, Tak PP. Rheumatoid arthritis synovium contains two subsets of CD83-DC-LAMP- dendritic cells with distinct cytokine profiles. Am J Pathol (2008) 172(4):940-50. doi:10.2353/ajpath.2008.070703

28. Sakkas LI, Platsoucas CD. Role of T cells in the pathogenesis of osteoarthritis. Arthritis Rheum (2002) 46(11):3112-3. doi:10.1002/art.10483

29. Symons JA, McCulloch JF, Wood NC, Duff GW. Soluble CD4 in patients with rheumatoid arthritis and osteoarthritis. Clin Immunol Immunopathol (1991) 60(1):72-82. doi:10.1016/0090-1229(91)90113-O

30. Dolganiuc A, Stavaru C, Anghel M, Georgescu E, Chichos B, Olinescu A. Shift toward T lymphocytes with Th1 and Tc1 cytokine-secterion profile in the joints of patients with osteoarthritis. Roum Arch Microbiol Immunol (1999) 58(3-4):249-58.

31. Hussein MR, Fathi NA, El-Din AM, Hassan HI, Abdullah F, Al-Hakeem E, et al. Alterations of the CD4(+), CD8 (+) T cell subsets, interleukins-1beta, IL-10, IL-17, tumor necrosis factor-alpha and soluble intercellular adhesion molecule-1 in rheumatoid arthritis and osteoarthritis: preliminary observations. Pathol Oncol Res (2008) 14(3):321-8. doi:10.1007/s12253-0089016-1

32. Sakata M, Masuko-Hongo K, Nakamura H, Onuma H, Tsuruha JI, Aoki $\mathrm{H}$, et al. Osteoarthritic articular chondrocytes stimulate autologous $\mathrm{T}$ cell responses in vitro. Clin Exp Rheumatol (2003) 21(6):704-10.

33. de Jong H, Berlo SE, Hombrink P, Otten HG, van Eden W, Lafeber FP, et al. Cartilage proteoglycan aggrecan epitopes induce proinflammatory autoreactive T-cell responses in rheumatoid arthritis and osteoarthritis. Ann Rheum Dis (2010) 69(1):255-62. doi:10.1136/ard.2008.103978

34. van de Putte LB, Meijer CJ, Lafeber GJ, Kleinjan R, Cats A. Lymphocytes in rheumatoid and nonrheumatoid synovial fluids. Nonspecificity of high T-cell and low B-cell percentages. Ann Rheum Dis (1975) 35(5):451-5. doi:10.1136/ ard.35.5.451

35. Haynes MK, Hume EL, Smith JB. Phenotypic characterization of inflammatory cells from osteoarthritic synovium and synovial fluids. Clin Immunol (2002) 105(3):315-25. doi:10.1006/clim.2002.5283

36. Nakamura H, Yoshino S, Kato T, Tsuruha J, Nishioka K. T-cell mediated inflammatory pathway in osteoarthritis. Osteoarthritis Cartilage (1999) 7(4):401-2. doi:10.1053/joca.1998.0224

37. Sanders ME, Makgoba MW, Sharrow SO, Stephany D, Springer TA, Young $\mathrm{HA}$, et al. Human memory T lymphocytes express increased levels of three cell adhesion molecules (LFA-3, CD2, and LFA-1) and three other molecules (UCHL1, CDw29, and Pgp-1) and have enhanced IFN-gamma production. J Immunol (1988) 140(5):1401-7.

38. Sakkas LI, Scanzello C, Johanson N, Burkholder J, Mitra A, Salgame P, et al. T cells and T-cell cytokine transcripts in the synovial membrane in patients with osteoarthritis. Clin Diagn Lab Immunol (1998) 5(4):430-7.

39. Johnell O, Hulth A, Henricson A. T-lymphocyte subsets and HLA-DRexpressing cells in the osteoarthritic synovialis. Scand J Rheumatol (1985) 14(3):259-64. doi:10.3109/03009748509100403

40. Yamada H, Nakashima Y, Okazaki K, Mawatari T, Fukushi J, Oyamada A, et al. Preferential accumulation of activated Th1 cells not only in rheumatoid arthritis but also in osteoarthritis joints. J Rheumatol (2011) 38(8):1569-75. doi:10.3899/jrheum.101355

41. Pawlowska J, Mikosik A, Soroczynska-Cybula M, Jozwik A, Luczkiewicz $\mathrm{P}$, Mazurkiewicz S, et al. Different distribution of CD4 and CD8 T cells in synovial membrane and peripheral blood of rheumatoid arthritis and 
osteoarthritis patients. Folia Histochem Cytobiol (2009) 47(4):627-32. doi:10.2478/v10042-009-0117-9

42. Chen K, Kolls JK. T cell-mediated host immune defenses in the lung. Annu Rev Immunol (2013) 31:605-33. doi:10.1146/annurev-immunol-032712100019

43. Raphael I, Nalawade S, Eagar TN, Forsthuber TG. T cell subsets and their signature cytokines in autoimmune and inflammatory diseases. Cytokine (2014) 74:5-17. doi:10.1016/j.cyto.2014.09.011

44. Ren W, Liu G, Chen S, Yin J, Wang J, Tan B, et al. Melatonin signaling in T cells: functions and applications. J Pineal Res (2017) 62(3):e12394. doi:10.1111/ jpi.12394

45. Zhang L, Li JM, Liu XG, Ma DX, Hu NW, Li YG, et al. Elevated Th22 cells correlated with Th17 cells in patients with rheumatoid arthritis. J Clin Immunol (2011) 31(4):606-14. doi:10.1007/s10875-011-9540-8

46. Zhang L, Li YG, Li YH, Qi L, Liu XG, Yuan CZ, et al. Increased frequencies of Th22 cells as well as Th17 cells in the peripheral blood of patients with ankylosing spondylitis and rheumatoid arthritis. PLoS One (2012) 7(4):e31000. doi:10.1371/journal.pone.0031000

47. Qi C, Shan Y, Wang J, Ding F, Zhao D, Yang T, et al. Circulating T helper 9 cells and increased serum interleukin-9 levels in patients with knee osteoarthritis. Clin Exp Pharmacol Physiol (2016) 43(5):528-34. doi:10.1111/1440-1681.12567

48. Partsch G, Wagner E, Leeb BF, Broll H, Dunky A, Smolen JS. T cell derived cytokines in psoriatic arthritis synovial fluids. Ann Rheum Dis (1998) 57(11):691-3. doi:10.1136/ard.57.11.691

49. Dolhain RJ, ter Haar NT, Hoefakker S, Tak PP, de Ley M, Claassen E, et al. Increased expression of interferon (IFN)-gamma together with IFN-gamma receptor in the rheumatoid synovial membrane compared with synovium of patients with osteoarthritis. Br J Rheumatol (1996) 35(1):24-32. doi:10.1093/ rheumatology/35.1.24

50. Shen PC, Wu CL, Jou IM, Lee CH, Juan HY, Lee PJ, et al. T helper cells promote disease progression of osteoarthritis by inducing macrophage inflammatory protein-1gamma. Osteoarthritis Cartilage (2011) 19(6):728-36. doi:10.1016/j.joca.2011.02.014

51. Chapoval S, Dasgupta P, Dorsey NJ, Keegan AD. Regulation of the T helper cell type 2 (Th2)/T regulatory cell (Treg) balance by IL-4 and STAT6. J Leukoc Biol (2010) 87(6):1011-8. doi:10.1189/jlb.1209772

52. Vahedi G, Poholek AC, Hand TW, Laurence A, Kanno Y, O'Shea JJ, et al. Helper T-cell identity and evolution of differential transcriptomes and epigenomes. Immunol Rev (2013) 252(1):24-40. doi:10.1111/imr.12037

53. Ren W, Wang K, Yin J, Chen S, Liu G, Tan B, et al. Glutamine-induced secretion of intestinal secretory immunoglobulin A: a mechanistic perspective. Front Immunol (2016) 7:503. doi:10.3389/fimmu.2016.00503

54. Wu M, Xiao H, Liu G, Chen S, Tan B, Ren W, et al. Glutamine promotes intestinal SIgA secretion through intestinal microbiota and IL-13. Mol Nutr Food Res (2016) 60(7):1637-48. doi:10.1002/mnfr.201600026

55. Pan HF, Leng RX, Li XP, Zheng SG, Ye DQ. Targeting T-helper 9 cells and interleukin-9 in autoimmune diseases. Cytokine Growth Factor Rev (2013) 24(6):515-22. doi:10.1016/j.cytogfr.2013.09.001

56. Zhao P, Xiao X, Ghobrial RM, Li XC. IL-9 and Th9 cells: progress and challenges. Int Immunol (2013) 25(10):547-51. doi:10.1093/intimm/dxt039

57. Schmitt E, Klein M, Bopp T. Th9 cells, new players in adaptive immunity. Trends Immunol (2014) 35(2):61-8. doi:10.1016/j.it.2013. 10.004

58. Kundu-Raychaudhuri S, Abria C, Raychaudhuri SP. IL-9, a local growth factor for synovial T cells in inflammatory arthritis. Cytokine (2016) 79:45-51. doi:10.1016/j.cyto.2015.12.020

59. Ivanov II, Zhou L, Littman DR. Transcriptional regulation of Th17 cell differentiation. Semin Immunol (2007) 19(6):409-17. doi:10.1016/j.smim. 2007.10.011

60. Wilson NJ, Boniface K, Chan JR, McKenzie BS, Blumenschein WM, Mattson JD, et al. Development, cytokine profile and function of human interleukin 17-producing helper T cells. Nat Immunol (2007) 8(9):950-7. doi:10.1038/ nil497

61. McGeachy MJ, Cua DJ. Th17 cell differentiation: the long and winding road. Immunity (2008) 28(4):445-53. doi:10.1016/j.immuni.2008.03.001

62. Shabgah AG, Fattahi E, Shahneh FZ. Interleukin-17 in human inflammatory diseases. Postepy Dermatol Alergol (2014) 31(4):256-61. doi:10.5114/ pdia.2014.40954
63. Floss DM, Schroder J, Franke M, Scheller J. Insights into IL-23 biology: from structure to function. Cytokine Growth Factor Rev (2015) 26(5):569-78. doi:10.1016/j.cytogfr.2015.07.005

64. Miossec P, Kolls JK. Targeting IL-17 and TH17 cells in chronic inflammation. Nat Rev Drug Discov (2012) 11(10):763-76. doi:10.1038/nrd3794

65. Ren W, Chen S, Zhang L, Liu G, Hussain T, Hao X, et al. Interferon tau affects mouse intestinal microbiota and expression of IL-17. Mediators Inflamm (2016) 2016:2839232. doi:10.1155/2016/2839232

66. Ren W, Yin J, Duan J, Liu G, Tan B, Yang G, et al. mTORC1 signaling and IL-17 expression: defining pathways and possible therapeutic targets. Eur J Immunol (2016) 46(2):291-9. doi:10.1002/eji.201545886

67. Xiao DF, Ren WK, Bin P, Chen S, Yin J, Gao W, et al. Chitosan lowers body weight through intestinal microbiota and reduces IL-17 expression via mTOR signalling. J Funct Foods (2016) 22:166-76. doi:10.1016/j.jff.2016. 01.009

68. Guo SY, Ding YJ, Li L, Zhang T, Zhang ZZ, Zhang ES. Correlation of CD(4) (+) $\mathrm{CD}(2)(5)(+) \operatorname{Foxp}(3)(+)$ Treg with the recovery of joint function after total knee replacement in rats with osteoarthritis. Genet Mol Res (2015) 14(3):7290-6. doi:10.4238/2015.July.3.4

69. Chabaud M, Durand JM, Buchs N, Fossiez F, Page G, Frappart L, et al. Human interleukin-17: a T cell-derived proinflammatory cytokine produced by the rheumatoid synovium. Arthritis Rheum (1999) 42(5):963-70. doi:10.1002/1529-0131(199905)42:5<963:AID-ANR15>3.0.CO;2-E

70. Sarkar S, Justa S, Brucks M, Endres J, Fox DA, Zhou X, et al. Interleukin (IL)$17 \mathrm{~A}, \mathrm{~F}$ and $\mathrm{AF}$ in inflammation: a study in collagen-induced arthritis and rheumatoid arthritis. Clin Exp Immunol (2014) 177(3):652-61. doi:10.1111/ cei. 12376

71. Trifari S, Kaplan CD, Tran EH, Crellin NK, Spits H. Identification of a human helper $\mathrm{T}$ cell population that has abundant production of interleukin 22 and is distinct from $\mathrm{T}(\mathrm{H})-17, \mathrm{~T}(\mathrm{H}) 1$ and $\mathrm{T}(\mathrm{H}) 2$ cells. Nat Immunol (2009) 10(8):864-71. doi:10.1038/ni.1770

72. Hori S, Nomura T, Sakaguchi S. Control of regulatory T cell development by the transcription factor Foxp3. Science (2003) 299(5609):1057-61. doi:10.1126/science. 1079490

73. Bommireddy R, Doetschman T. TGFbetal and Treg cells: alliance for tolerance. Trends Mol Med (2007) 13(11):492-501. doi:10.1016/ j.molmed.2007.08.005

74. Carrier Y, Yuan J, Kuchroo VK, Weiner HL. Th3 cells in peripheral tolerance. I. Induction of Foxp3-positive regulatory T cells by Th3 cells derived from TGF-beta T cell-transgenic mice. JImmunol (2007) 178(1):179-85. doi:10.4049/jimmunol.178.1.179

75. Miyara M, Sakaguchi S. Natural regulatory T cells: mechanisms of suppression. Trends Mol Med (2007) 13(3):108-16. doi:10.1016/j.molmed.2007.01.003

76. Yudoh K, Matsuno H, Nakazawa F, Yonezawa T, Kimura T. Reduced expression of the regulatory CD4+ $\mathrm{T}$ cell subset is related to $\mathrm{Th} 1 / \mathrm{Th} 2$ balance and disease severity in rheumatoid arthritis. Arthritis Rheum (2000) 43(3):61727. doi:10.1002/1529-0131(200003)43:3<617:AID-ANR19>3.0.CO;2-B

77. Moradi B, Schnatzer P, Hagmann S, Rosshirt N, Gotterbarm T, Kretzer JP, et al. CD4(+)CD25(+)/highCD127low/(-) regulatory T cells are enriched in rheumatoid arthritis and osteoarthritis joints - analysis of frequency and phenotype in synovial membrane, synovial fluid and peripheral blood. Arthritis Res Ther (2014) 16(2):R97. doi:10.1186/ar4545

78. Li S, Wan J, Anderson W, Sun H, Zhang H, Peng X, et al. Downregulation of IL-10 secretion by Treg cells in osteoarthritis is associated with a reduction in Tim-3 expression. Biomed Pharmacother (2016) 79:159-65. doi:10.1016/ j.biopha.2016.01.036

79. Ueno H, Banchereau J, Vinuesa CG. Pathophysiology of T follicular helper cells in humans and mice. Nat Immunol (2015) 16(2):142-52. doi:10.1038/ ni.3054

80. Crotty S. Follicular helper CD4 T cells (TFH). Annu Rev Immunol (2011) 29:621-63. doi:10.1146/annurev-immunol-031210-101400

81. Simpson N, Gatenby PA, Wilson A, Malik S, Fulcher DA, Tangye SG, et al. Expansion of circulating $\mathrm{T}$ cells resembling follicular helper $\mathrm{T}$ cells is a fixed phenotype that identifies a subset of severe systemic lupus erythematosus. Arthritis Rheum (2010) 62(1):234-44. doi:10.1002/art. 25032

82. Chu Y, Wang F, Zhou M, Chen L, Lu Y. A preliminary study on the characterization of follicular helper $\mathrm{T}$ (Tfh) cells in rheumatoid arthritis synovium. Acta Histochem (2014) 116(3):539-43. doi:10.1016/j.acthis.2013.10.009 
83. Shan Y, Qi C, Liu Y, Gao H, Zhao D, Jiang Y. Increased frequency of peripheral blood follicular helper T cells and elevated serum IL21 levels in patients with knee osteoarthritis. Mol Med Rep (2017) 15(3):1095-102. doi:10.3892/ mmr.2017.6132

84. Kuryliszyn-Moskal A. Comparison of blood and synovial fluid lymphocyte subsets in rheumatoid arthritis and osteoarthritis. Clin Rheumatol (1995) 14(1):43-50. doi:10.1007/BF02208083

85. Sohen S, Romain PL, Rothstein DM, Yamane T, Tanaka S, Anderson P, et al. Phenotypic abnormalities in CD8+ T lymphocyte subsets in patients with rheumatoid arthritis. J Rheumatol (1991) 18(11):1649-54.

86. Reidbord HE, Osial TA Jr. Synovial lymphocyte subsets in rheumatoid arthritis and degenerative joint disease. J Rheumatol (1987) 14(6):1089-94.

87. Hsieh JL, Shiau AL, Lee CH, Yang SJ, Lee BO, Jou IM, et al. CD8+ $\mathrm{T}$ cell-induced expression of tissue inhibitor of metalloproteinses-1 exacerbated osteoarthritis. Int J Mol Sci (2013) 14(10):19951-70. doi:10.3390/ ijms141019951

88. Ezawa K, Yamamura M, Matsui H, Ota Z, Makino H. Comparative analysis of CD45RA- and CD45RO-positive CD4+T cells in peripheral blood, synovial fluid, and synovial tissue in patients with rheumatoid arthritis and osteoarthritis. Acta Med Okayama (1997) 51(1):25-31.

89. Volin MV, Shah MR, Tokuhira M, Haines GK, Woods JM, Koch AE. RANTES expression and contribution to monocyte chemotaxis in arthritis. Clin Immunol Immunopathol (1998) 89(1):44-53. doi:10.1006/clin. 1998.4590

90. Mathieu A, Mereu MC, Pisano L. T gamma lymphocytes of peripheral blood and synovial fluid in rheumatoid arthritis: quantitative determination and qualitative analysis. Arthritis Rheum (1981) 24(5):658-61. doi:10.1002/ art.1780240505

91. Andreu JL, Trujillo A, Alonso JM, Mulero J, Martinez C. Selective expansion of $\mathrm{T}$ cells bearing the gamma/delta receptor and expressing an unusual repertoire in the synovial membrane of patients with rheumatoid arthritis. Arthritis Rheum (1991) 34(7):808-14. doi:10.1002/art.1780340705

92. Jacobs MR, Haynes BF. Increase in TCR gamma delta T lymphocytes in synovia from rheumatoid arthritis patients with active synovitis. J Clin Immunol (1992) 12(2):130-8. doi:10.1007/BF00918143

93. Meliconi R, Uguccioni M, D’Errico A, Cassisa A, Frizziero L, Facchini A. T-cell receptor gamma-delta positive lymphocytes in synovial membrane. Br J Rheumatol (1992) 31(1):59-61. doi:10.1093/rheumatology/ 31.1.59

94. Cauli A, Pitzalis C, Yanni G, Awad M, Panayi GS. CD1 expression in psoriatic and rheumatoid arthritis. Rheumatology (Oxford) (2000) 39(6):666-73. doi:10.1093/rheumatology/39.6.666
95. Godfrey DI, Uldrich AP, McCluskey J, Rossjohn J, Moody DB. The burgeoning family of unconventional T cells. Nat Immunol (2015) 16(11):1114-23. doi:10.1038/ni.3298

96. Ren W, Chen S, Yin J, Duan J, Li T, Liu G, et al. Dietary arginine supplementation of mice alters the microbial population and activates intestinal innate immunity. J Nutr (2014) 144(6):988-95. doi:10.3945/jn.114.192120

97. Ren W, Duan J, Yin J, Liu G, Cao Z, Xiong X, et al. Dietary L-glutamine supplementation modulates microbial community and activates innate immunity in the mouse intestine. Amino Acids (2014) 46(10):2403-13. doi:10.1007/s00726-014-1793-0

98. Ren W, Yin J, Duan J, Liu G, Zhu X, Chen S, et al. Mouse intestinal innate immune responses altered by enterotoxigenic Escherichia coli (ETEC) infection. Microbes Infect (2014) 16(11):954-61. doi:10.1016/j.micinf. 2014.09.005

99. Ren W, Yin J, Wu M, Liu G, Yang G, Xion Y, et al. Serum amino acids profile and the beneficial effects of L-arginine or L-glutamine supplementation in dextran sulfate sodium colitis. PLoS One (2014) 9(2):e88335. doi:10.1371/ journal.pone.0088335

100. Ren W, Yin J, Chen S, Duan J, Liu G, Li T, et al. Proteome analysis for the global proteins in the jejunum tissues of enterotoxigenic Escherichia coli -infected piglets. Sci Rep (2016) 6:25640. doi:10.1038/srep25640

101. Perl A. Activation of mTOR (mechanistic target of rapamycin) in rheumatic diseases. Nat Rev Rheumatol (2016) 12(3):169-82. doi:10.1038/ nrrheum.2015.172

102. Honda K, Littman DR. The microbiota in adaptive immune homeostasis and disease. Nature (2016) 535(7610):75-84. doi:10.1038/nature18848

103. Thaiss CA, Zmora N, Levy M, Elinav E. The microbiome and innate immunity. Nature (2016) 535(7610):65-74. doi:10.1038/nature18847

104. Huang Z, Kraus VB. Does lipopolysaccharide-mediated inflammation have a role in OA? Nat Rev Rheumatol (2016) 12(2):123-9. doi:10.1038/ nrrheum.2015.158

Conflict of Interest Statement: The authors declare that the research was conducted in the absence of any commercial or financial relationships that could be construed as a potential conflict of interest.

Copyright (c) $2017 \mathrm{Li}, \mathrm{Luo}, \mathrm{Zhu}$ and Lei. This is an open-access article distributed under the terms of the Creative Commons Attribution License (CC BY). The use, distribution or reproduction in other forums is permitted, provided the original author(s) or licensor are credited and that the original publication in this journal is cited, in accordance with accepted academic practice. No use, distribution or reproduction is permitted which does not comply with these terms. 